\title{
O tema da formação de professores: trajetórias e tendências do campo na pesquisa e na ação
}

Maria Isabel da Cunha'

\begin{abstract}
Resumo
O conhecimento dos movimentos epistemológicos, culturais e políticos que definiu, em uma perspectiva histórica, a compreensão do campo da formação de professores, pode ser uma significativa contribuição para a prática da formação. Entender esse processo na sua dimensão evolutiva favorece o entendimento da complexidade desse campo de conhecimento e as múltiplas influências que se estabelecem sobre ele. 0 objetivo deste trabalho, portanto, é mapear e estudar as tendências teórico-práticas que marcaram a compreensão da docência no Brasil, preferencialmente no período que se inicia na segunda metade do século XX. 0 trabalho reconhece sua condição aleatória e não pretende exclusividade a respeito do tema. A partir do mapeamento realizado, conclui-se que as diferentes tendências teórico-práticas para a docência tiveram significativos impactos nas pesquisas educacionais e essas, por sua vez, também exerceram um papel de protagonismo nas mudanças paradigmáticas que atingiram a formação de professores. Na medida em que o paradigma da racionalidade técnica foi dando lugar à compreensão do fenômeno educativo como produzido social e culturalmente, houve significativas mudanças nas formas de produzir conhecimento na área da educação. Todas as fases que marcam as tendências dos estudos a respeito da formação de professores produziram conceitos e se apresentaram como produtos e produtoras das ações formativas, influenciando e sendo influenciadas pelas políticas, legislações e culturas.
\end{abstract}

\section{Palavras-chave}

Formação de professores - Tendências teórico-práticas para a docência - Políticas de formação docente - Desenvolvimento profissional docente.

I- Universidade do Vale do Rio dos Sinos, 


\title{
The theme of teacher education: trajectories and trends of the field in research and action
}

Maria Isabel da Cunha'

\begin{abstract}
The knowledge of the epistemological, cultural and political movements which defined, from a historical perspective, the understanding of the field of teacher education can be a significant contribution to the practice of education. Understanding this process in its evolutionary dimension favors understanding the complexity of this field of knowledge and the multiple influences that are established in it. Therefore, this study aims to map and study the theoretical and practical trends which marked the understanding of teaching in Brazil, preferably in the period beginning in the second half of the twentieth century. The work recognizes its random condition and does not demand exclusivity. From the mapping done, it is concluded that the different theoretical and practical trends for teaching had a significant impact on educational research and this, in turn, also played a leading role in the paradigmatic changes that have hit teacher education. As the paradigm of technical rationality gave way to an understanding of the educational phenomenon as socially and culturally produced, there were significant changes in ways of producing knowledge in the education area. All the phases that mark the trends of the studies on teacher education have produced concepts and presented themselves as products and producers of educational actions, influencing and being influenced by policies, legislations and cultures.
\end{abstract}

\section{Keywords}

Teacher education - Theoretical and practical trends for teaching Policies on teacher education - Teacher professional development.

I- Universidade do Vale do Rio dos Sinos, São Leopoldo, RS, Brazil. Contact:mabel@unisinos.br 
Refletir a respeito do conceito de formação de professores exige que se recorra à pesquisa, à prática de formação e ao próprio significado do papel do professor na sociedade. A pesquisa acompanha os movimentos político-econômicos e socioculturais que dão forma ao desempenho docente, quer no plano do real, quer no ideal. Já a prática estabelece-se a partir de uma amálgama de condições teórico-contextuais.

Nessa direção, este estudo enfoca, em uma visada contemporânea e tendo como base a realidade brasileira, os diferentes contornos do papel docente, produzidos socialmente, em um tempo e lugar, os quais favorecem a apreensão conceitual da formação de professores. Não há, no exercício de análise feito neste artigo, a pretensão de esgotamento do tema, nem a de reivindicar exclusividade quanto à mirada teórica. 0 objetivo foi o de estimular sínteses que favoreçam a compreensão da trajetória da formação de professores no Brasil, em uma perspectiva processual. Com isso, espera-se contribuir com os estudiosos do tema, especialmente as novas gerações, e auxiliá-los a inteirarem-se dos movimentos vividos nesse campo de estudos, no qual, certamente, há tensões e compreensões subjetivas em jogo.

\section{Formação de professores:}

dimensão conceitual

Comecemos nossa reflexão teórica a partir do entendimento de Estevão (2001, p. 185) a respeito da formação:

a formação como uma prática social específica e como uma verdadeira instituição que cumpre certas funções sociais relacionadas com a reprodução, regulação e legitimação do sistema social. [...] a formação, ao mesmo tempo, celebra determinados valores, por vezes contraditórios, ligados quer ao mundo empresarial e gerencialista, quer ao mundo cívico e da cidadania.

Se a concepção de formação não é neutra, como mostrou a citação acima, torna-se imprescindivel analisá-la a partir de uma perspectiva que se distancie da compreensão meramente técnica, afastando qualquer possibilidade de negação da subjetividade.

Gauthier (1999, p. 24) registrou, com propriedade, que:

[...] cada dispositivo do olhar e da observação modifica o objeto de estudo [...] por isso, nunca estudamos um objeto neutro, mas sempre um objeto implicado, caracterizado pela teoria e pelo dispositivo que permite vê-lo, observá-lo e conhecê-lo.

Nessa perspectiva, é importante uma reflexão sistematizada a respeito da formação de professores, pois em muitas situações a pesquisa, mesmo considerando sua natural condição questionadora, pode assumir uma relativa contribuição para processos educativos emancipatórios. Assim, o conhecimento tanto pode ser um lugar de resistência à regulação imposta, como servir de instrumento de poder em um contexto discursivo determinado.

0 paradigma da ciência moderna, fortemente inspirador das ciências exatas e naturais, marcou a trajetória das ciências sociais no seu intento de legitimidade. Nele, muitas vezes, a formação de professores foi tratada em uma dimensão eminentemente neutra, quer na sua inspiração pedagógica, quer na perspectiva psicológica.

Assumindo uma posição valorativa explícita, Arroyo (2004) defendeu uma humana formação, extrapolando a usual interpretação que confına a formação aos espaços e tempos determinados. Para o autor,

A pedagogia nasce quando se reconhece que essa formação, envolvendo a idéia de fabricar o mundo humano, faz parte de um projeto, uma tarefa intencional, consciente. (ARROYO, 2004, p. 226)

Decorrente e em conformidade com essa posição, é possível afirmar que, em sentido amplo, a formação de professores se faz em 
um continuum, desde a educação familiar e cultural do professor até a sua trajetória formal e acadêmica, mantendo-se como processo vital enquanto acontece seu ciclo profissional. Nesse contexto, é possível mencionar um processo formativo docente (ISAIA, 2006) que engloba:

\section{[...] tanto o desenvolvimento pessoal} quanto o profissional dos professores, contemplando de forma inter-relacionada ações auto, hétero e interformativas. (ISAIA, 2006, p. 351)

Tendo em vista uma dimensão mais pontual, a literatura vem assumindo, enquanto possibilidades formais de desenvolvimento profissional dos professores, dois espaços preferencias: o da formação inicial e o da formação continuada. Por formação inicial entendem-se os processos institucionais de formação de uma profissão que geram a licença para o seu exercício e o seu reconhecimento legal e público. Os cursos de licenciatura, segundo a legislação brasileira, são os responsáveis pela formação inicial de professores para atuação nos níveis fundamental e médio e devem corresponder ao que a legislação propõe em relação aos seus objetivos, formatos e duração.

Já a formação continuada refere-se a iniciativas instituídas no período que acompanha o tempo profissional dos professores. Pode ter formatos e duração diferenciados, assumindo a perspectiva da formação como processo. Tanto pode ter origem na iniciativa dos interessados como pode inserir-se em programas institucionais. Nesse caso, os sistemas de ensino, as universidades e as escolas são as principais agências mobilizadoras dessa formação.

\section{Formação de professores:}

desenvolvimento da trajetória do conceito, teorias e autorias principais

A literatura pedagógica tem informado, com bastante frequência, a respeito das pesquisas acerca do professor e sua formação que vêm sendo realizadas ao longo do tempo. Como é compreensível, essas investigações estão intimamente relacionadas com as perspectivas políticas e epistemológicas que vêm definindo a função do professor através dos tempos. Entretanto, para refletir acerca da formação de professores como um problema que incita múltiplos estudos, eventos, diretrizes e políticas, é preciso ampliar a abrangência do foco.

Essa ampliação se justifica porque o professor é um profissional que, salvo em situações raras, exercita a sua atividade em locais específicos: a escola e a universidade. Essa condição induz à reflexão segundo a qual "é improvável poder abordar a temática da docência separada do lugar em que se produz enquanto profissão" (CUNHA, 2006, p. 56). Não há professores no vazio, em uma visão etérea, propondo deslocamentos entre sujeito e contexto. 0 professor se faz professor em uma instituição cultural e humana, depositária de valores e expectativas de uma determinada sociedade, compreendida em um tempo histórico.

Esse pressuposto ajuda na compreensão e análise das tendências investigativas no campo da formação de professores que ora oscilaram sobre o ensino e a escola, ora centraram seu olhar mais especificamente na figura do professor. Assim, percebe-se, pela análise da literatura especializada, que, até o início da década de 80 , os estudos de origem norte-americana foram os mais divulgados em nosso país e os que mais influenciaram os pesquisadores brasileiros. Entre as primeiras pesquisas de que se tem conhecimento estão aquelas que, inspiradas na organização industrial e tendo como pressuposto as ideias de produtividade e controle, centraram-se na teoria da organização do trabalho e procuraram subsidiar as questões administrativas dos sistemas escolares (SANT'ANNA, 1976).

Acerca do ensino propriamente dito, cabe ressaltar os estudos de Gage (1963), os quais mostram que a investigação a respeito do professor iniciou-se quando se pretendeu estudar a eficácia do ensino. Além disso, é importante 
salientar as investigações de Grujot (apud POSTIC, 1979), que propunham uma relação entre o valor profissional do professor e a sua capacidade de fazer os alunos compreenderem as informações. Para esse autor, a qualidade do ato pedagógico medir-se-ia pela qualidade da transmissão do saber do professor.

Outra proposta, digna de nota, foi apresentada na década de cinquenta por Remmers e Gage (1963). Partia do pressuposto de que “[...] o melhor educador é aquele que produz o máximo de mudanças desejáveis nos seus alunos, em um grau mais elevado" (POSTIC, 1979, p. 31). Geralmente, esse tipo de pesquisa analisava o desenvolvimento de aptidões e os conhecimentos dos alunos, que eram medidos antes e após a influência do professor. Essa proposição suscitou algumas críticas, não pelo que representava sob o aspecto conceitual, mas pela dificuldade de aferição e afastamento de variáveis correlatas. A ideia de que a competência do professor era avaliada pelo produto, e que esse era resultante das condições objetivas do ensino, parecia absolutamente aceita.

Nesses estudos, partia-se do pressuposto de que a competência do professor era um traço único. Desse modo, aquele que conseguisse estimular o desenvolvimento de uma aptidão para o máximo de alunos seria igualmente capaz de fazê-los progredir em qualquer outra situação e/ou seria capaz do mesmo feito com qualquer categoria de alunos. De natureza nitidamente comportamentalista, essa vertente foi bastante presente nas pesquisas brasileiras, nos anos 1970, que versavam acerca do comportamento docente.

Os estudos a respeito da eficácia do professor foram, aos poucos, deslocando-se para a investigação do próprio ato de ensino. 0 principal exemplo dessa tendência, com forte presença no espaço nacional, foram as vertentes que se voltaram para a análise do processo de interação no espaço da sala de aula. Dos estudiosos do assunto, Flanders (1960) foi o mais divulgado. A análise das interações constituía-se como uma técnica para apreender qualitativa e quantitativamente as dimensões do comportamento verbal do professor na sala de aula e partia da ideia de que a medida da influência do comportamento do professor sobre o trabalho dos alunos é um meio direto para avaliar a eficácia do professor.

$\mathrm{Na}$ mesma perspectiva dos estudos de Flanders, mais alguns foram realizados tendo como foco os aspectos afetivos e interacionais do ensino. Dessas pesquisas, evoluíram outras que centraram sua atenção nas condições cognitivas do ato de ensinar. A forma de proposição do conteúdo e dos processos mentais, provocados nos alunos, seriam indicadores da competência do professor. Gage (1963) e Meux Schmith (1997) elaboraram critérios de avaliação do ato de ensinar a partir de categorias cognitivas, relacionando processos de pensamento com habilidades de ensino. Outros estudos de base cognitiva continuaram a ser realizados. Os de Gallangher (1967) e Aschner (1963), usando o modelo tridimensional de Guilford, distinguiram a influência e a relação entre o comportamento verbal do professor e os processos dominantes no pensamento dos estudantes.

Em que pese o esforço desses estudiosos em contribuir para o melhor entendimento do processo de ensinar e, portanto, da formação de professores, recaiu sobre eles a crítica de reduzir a complexidade da situação pedagógica a uma constelação de estímulos isolados, próprios da visão behaviorista.

No Brasil, todavia, a repercussão dos referidos estudos foi significativa, veiculada, sobretudo, por meio dos programas de pósgraduação que se instalaram no início da década de 1970. Feldens (1984) mostrou, por meio de um estudo dos artigos publicados em revistas nacionais acerca da temática da formação de professores, que tais artigos poderiam ser agrupados em seis categorias de análise. Três delas referiam-se às características do professor, competências docentes e processos interativos, sendo que as demais se ligavam a programas de formação e treinamento. 0 referencial teórico e metodológico utilizado 
era preponderantemente norte-americano, confirmando a forte influência cultural e acadêmica desses estudiosos no Brasil.

A partir de então, foram criando espaço para as investigações que focalizavam o professor sob a perspectiva psicológica. Morrison e McIntire (1971), que tiveram seus escritos traduzidos no Brasil, defenderam que o professor deveria apresentar determinados traços de personalidade, atitudes e interesses sociais que provocassem um bom nível de satisfação nos alunos.

Lembo (1975) investigou o desempenho do professor em função de suas frustrações e propôs alternativas que pudessem evitar o fracasso escolar. De modo geral, a maior parte das pesquisas estava ligada à vivência psicológica do professor e ao papel que desempenhava na escola, na família e na comunidade.

Juan Mosquera (1976), por exemplo, reuniu e ressignificou proposições de autores estrangeiros sobre o tema. 0 autor afirmou que:

Toda e qualquer revolução pedagógica deve levar em conta a afetividade do educador, pois suas aptidões afetivas são fundamentais para o mundo do futuro. (MOSQUERA, 1976, p. 105)

Os estudos do autor, já com chancela nacional, tiveram importante repercussão nas pesquisas e nas práticas de formação de professores que procuravam a valorização de aspectos psicológicos na construção da docência.

$\mathrm{Na}$ mesma direção, as ideias de Rogers (1971) entusiasmaram muitos educadores brasileiros, representando uma visão progressista no espaço tecnicista dos anos setenta. Perkins (apud MOSQUERA, 1976) também teve sua vez, reforçando a empatia e o autoconceito como categoria nuclear para o professor promover o relacionamento interpessoal.

Com o distanciamento possível, em uma análise atual, é possível constatar que os aspectos psicológicos representavam, na época, uma forte corrente na pesquisa a respeito da formação de professores. Parece que mesmo os estudos sociológicos e antropológicos preocupavamse com as questões do status social ou da adaptação do sujeito em determinada cultura. Porém, não explicitavam as relações de poder e/ou dominação de classe subjacente às formas de produção. 0 professor e os alunos pareciam ser entendidos como seres abstratos, existindo independente de tempo e espaço, para os quais a história e a estrutura social pouco contavam.

A compreensão da dimensão política da educação interferiu muito na forma de compreender o papel do professor e, por conseguinte, sua formação. 0 início da década de oitenta, no Brasil, marcou a possibilidade de serem estabelecidos novos olhares diante da função docente, entendendo o professor dentro da estrutura de poder da sociedade, na qual a identidade é concebida como uma construção social e cultural. A contribuição de Paulo Freire nesse sentido foi insuperável. 0 autor ensinou que o professor é um ser do mundo e não pode ser pensado fora dessa perspectiva; não é um indivíduo isolado, mas, sim, "um ser em situação, um ser do trabalho e da transformação [...]" (FREIRE, 1992, p. 28).

Os programas de pós-Graduação colocaram-se na vanguarda da discussão acadêmica, vista também como espaço político. Em nosso país, os estudos de Mello (1982), Nosella (1983), Vieitez (1982) e Luckesi (1983) inauguraram uma nova etapa de análise da competência docente nas dimensões técnica e política. Tais estudiosos foram inspirados nas contribuições de raiz marxista, feita por Saviani (1981), Gadotti (1980), Rodrigues (1985) e outros educadores brasileiros. A formação de professores começou então a ser questionada e ampliada na sua compreensão, incorporando dimensões culturais e subjetivas que até aquele momento estavam ausentes dos estudos a respeito da docência.

Os eventos nacionais retomados, como Sociedade Brasileira para o Progresso da Ciência - SBPC; Conferência Brasileira de Educação CBE e Encontro Nacional de Didática e Prática 
de Ensino - ENDIPE, tornavam-se espaços privilegiados para grandes discussões políticas e acadêmicas. Tais eventos materializavam o esforço de entidades nacionais que floresciam, como Associação Nacional de Educação ANDE; Associação Nacional de Docentes da Educação Superior - ANDES; Associação Nacional de Pesquisa e Pós-Graduação em Educação ANPED; e Centro de Estudos sobre Educação e Sociedade. - CEDES.

Naquele momento, a pesquisa educacional voltava-se para os referenciais filosóficos e sociológicos, uma vez que estava preocupada com os grandes problemas do país, na fase de reconstrução democrática. A temática da formação de professores estava na pauta dos governos estaduais, recém-eleitos no contexto da abertura política, que procuravam, na academia, intelectuais engajados para seus quadros. Havia uma emergência para novas práticas que dessem encaminhamentos às demandas reais dos sistemas educacionais públicos, as quais ficavam a cargo dos estados.

Ao mesmo tempo, a lógica positivista de fazer ciência começava a dar sinais de esgotamento no suporte das pesquisas educacionais. 0 novo discurso, incorporando as concepções da dialética, tornava-se incompatível com a visão epistemológica da ciência moderna. A inquietação com o espaço concreto da prática pedagógica deu lugar às chamadas metodologias qualitativas da pesquisa, rompendo com a lógica da neutralidade e da quantificação (CUNHA, 1993).

Nesse movimento, as pesquisas do tipo pesquisa-ação, participantes, fenomenológicas, histórias de vida e etnográficas começaram a povoar as dissertações e teses, bem como as investigações dos docentes universitários. No chão da escola produziam-se movimentos reivindicando maior autonomia dos coletivos institucionais e protagonizando experiências inovadoras, que pretendiam a ruptura com as práticas tradicionais de ensinar e aprender.

A temática da formação de professores foi atingida por tais movimentos, reconfigurações e estímulos. Nesse sentido, os estudos que se distanciavam da racionalidade técnica foram muito importantes e passaram a constituir uma base nacional de produção investigativa. Como resultado dessas investigações, foi criada a Associação Nacional de Formação de Professores (ANFOPE), que reuniu pesquisadores e dirigentes universitários envolvidos com o campo da pedagogia e da formação de professores. Essa associação assumiu uma condição política importante, fazendo interlocuções com as autoridades ministeriais e o congresso brasileiro, o qual legislaria sobre o tema.

Lüdke e André (1986), Fazenda (1995), Veiga (1988), Cunha (1989), Martins (1982), Pimentel (1993), Pimenta (1994), Penin (1994) e tantos outros investigadores nacionais se incorporaram às contribuições internacionais de estudiosos como Schulman (1989), Gimeno Sacristán (1989), Nóvoa (1992), Schön (1983), Zeichner (1992, 1995), Perrenoud (1993), Contreras (1994) entre outros.

A perspectiva de estudar o professor como sujeito concreto da ação pedagógica contribuiu para entendê-lo na sua constituição técnica, pessoal e profissional. Esse desdobramento passou a ganhar espaço nos estudos que relacionavam educação e trabalho, tendo como suporte os referenciais sociológicos. A profissão docente, na sua condição social de exercício, incorporou aspectos da cultura, do gênero e da etnia como integrantes de sua configuração. Inseriram-se nesses interesses investigativos os estudos de Arroyo (1985), Abraamo (1987), Silva (2000), Louro (1989), Lopes (1991), Costa (1995), Hypólito (1991), Pessanha (1994) e outros. No âmbito internacional, foram importantes as contribuições de Varela (1992), Apple (1989), Enguita (1991), Nóvoa (1992) e Guerrero (1992), que repercutiram no Brasil.

Nesse contexto, as reflexões teóricas e as produções advindas da pesquisa influenciavam os movimentos de discussão da profissão docente, tanto nas condições de seu exercício cotidiano como de sua formação. Reivindicava-se que, no Brasil, a formação de todos os professores 
ocorresse em nível superior e que houvesse uma base nacional fundamentando a organização curricular dos cursos de licenciaturas.

A base cultural da docência, percebida como uma produção histórica, também foi aceita pelos estudiosos da área, que incorporaram essa dimensão como um valor. Dela, decorreu uma valorização da subjetividade, ou melhor, das subjetividades, instalando a discussão do sujeito histórico da transformação social. 0 professor assumia-se na história como sujeito e, para além das dimensões psicológica, política e profissional, reconhecia-se sua inserção na cultura, em que a contingência global convive com os determinismos locais.

Contraditoriamente, uma nova etapa no mapa da economia política mundial, com a simbólica queda do Muro de Berlim, estabeleceu-se tanto no nível social como político. A segunda metade dos anos 90 trouxe o avanço do chamado neoliberalismo, reconfigurando o capitalismo de forma exacerbada e anunciando o fim das utopias solidárias. 0 encolhimento do estado se estabeleceu como principal bandeira, reconhecendo o mercado como fundamental força reguladora das relações humanas. Para alcançar com maior êxito a lógica da globalização, defendia-se o significativo enfraquecimento da concepção de nação, alterando as bases produtivas e as relações de dependência entre pobres e ricos. As políticas de fortalecimento de blocos econômicos, consequentemente, impactaram seriamente as identidades nacionais, com repercussões significativas em suas instituições, entre elas, a universidade.

Ainda com perplexidade, a educação em geral, e a universidade, em particular, viram-se em um embate entre a democratização e a resposta às exigências de um mundo produtivo cambiante. Novas configurações se apresentaram como inevitáveis e com facilidade se produziu um neotecnicismo pedagógico para responder às exigências do mercado, principalmente por meio dos parâmetros da qualidade total e da pedagogia das competências.
0 discurso das competências foi institucionalizado através da nova Lei de Diretrizes e Bases da Educação Nacional (LDB), promulgada em 1996, e pelos consequentes Parâmetros Curriculares Nacionais (PCNs) dos diversos níveis de ensino e carreiras profissionais. A inclusão do termo competências não significava, nesse contexto, apenas uma figura de linguagem; revelava uma articulação de maior dependência entre os sistemas educativos e as exigências do mundo produtivo, colocando o professor, mais uma vez, como artífice de uma pedagogia, em grande parte, predeterminada.

Nesse contexto, a função docente materializa-se pela ação instrumental de favorecer o alcance das competências por parte de seus alunos. 0 espanhol César Coll (1987) e o franco-canadense Philippe Perrenoud (1993) deram a principal sustentação teórica para essa legislação e influenciaram significativamente a sua elaboração.

0 impacto das políticas econômicas, internacionais e nacionais, sobre os sistemas educativos redundou na emergente discussão a respeito do espaço da formação de professores, tomando como referência para tal termo o enfoque sociogeográfico, que entende o espaço não apenas como uma unidade física, mas, também, e com mais importância, como uma defınição de poder. Com inspiração em Giddens (1984), é possível afirmar que o homem faz sua própria geografia e, também, sua história. Para o autor,

[...] as configurações espaciais da vida social são uma questão de importância fundamental para a teoria social, tanto como o são as dimensões de temporalidade. (GIDDENS, 1984, p. 363)

A discussão anterior, que colocava as questões da formação de professores analisadas sob o ângulo da epistemologia e da pedagogia, tomou um novo sentido. Considerando ainda absolutamente pertinentes as reflexões que abordam as relações entre ensino e pesquisa 
ou entre teoria e prática, houve uma impulsão, pelas medidas políticas, para reordenar o foco da discussão.

0 lugar da formação, antes apenas visto como uma questão de propriedade formativa, passou a exigir análises no âmbito das estratégias políticas. Nesse contexto, as ideias de Hargreaves (1999) a respeito da geografia social da formação docente precisam ser destacadas, pois reforçam a ideia de que o espaço em que se dá a formação docente constituiu-se como importante, podendo modificar e acrescentar contingências às trajetórias gerais da formação, tornando-se uma característica relevante das instituições e das interações humanas.

Ao destacar a importância do lugar da formação, Hargreaves (1999) afırmou que onde se situa e se distribui a formação de professores é uma questão tão importante como a que aborda o quando se criou e como evoluiu essa formação em um entorno determinado. Nessa perspectiva, o espaço da formação tem um sentido de inclusão/exclusão que, especialmente na reestruturação capitalista da última década, tem profundos significados sociais na estrutura de poder da ordem mundial.

Para o autor, a geografia social atual abarca a marginalidade espacial e a desinstitucionalização da formação de professores desde a universidade. Com ela se estabelece uma nova utilização de outros lugares e espaços, criando certo confinamento simbólico. Nessa modalidade estariam instituídas as escolas de desenvolvimento profissional (os institutos superiores de educação), como formas concretas de representar as práticas seletivas e aceitas para a formação docente e onde se poderiam integrar os interesses práticos, além daqueles da universidade. Nessa compreensão, como afırma Milton Santos (1997, p. 20):

[...] o que globaliza, separa; é o local que permite a união [...] caracterizado por dois gêneros de constituição: uma é a própria configuração territorial; outra é a norma, a organização, os regimes de regulação. 0 lugar e a região não são mais o fruto de uma solidariedade orgânica, mas de uma solidariedade regulada ou organizacional.

Esse argumento, construído para entender a temática da aceleração contemporânea, encaixa-se perfeitamente à lógica que justifica a criação de um espaço próprio para a formação de professores fora da universidade. Isso porque, nessa perspectiva, representaria as inadequações dos espaços globais que deveriam dar lugar aos espaços que preservassem o específico e o fizessem funcionar mais adequadamente. Com relação ao lugar específico, Santos (1997, p. 18) afirmou que esse "torna-se o mundo do veraz e da esperança, e o global, mediatizado por uma organização perversa, constitui-se numa ameaça”, certamente descaracterizadora das possibilidades locais.

0 irônico dessa discussão é constatar que a defesa de uma formação acadêmica mais ampla do futuro professor poderia ser utilizada como uma tese favorável à globalização, fortalecendo o argumento de que os espaços generalistas e teóricos anulariam os esforços para a construção de um conhecimento próprio da formação docente, que incluísse os saberes da prática cotidiana. Foi preciso, então, delatar essa possibilidade falaciosa. Mais grave do que essa condição, pode ser o risco de confinamento da formação em espaços em que não haja trânsito de ideias e conhecimentos gerais e multidisciplinares.

0 desafio parece ser, portanto, a articulação entre o local e o global; entre os marcos teóricos mais amplos e o cotidiano. Novamente lançamos mão das palavras de Milton Santos (1997, p.16), quando afirma que "o espaço se globaliza, mas não é mundial como um todo, senão como metáfora [...] quem pode se globalizar são as pessoas e os lugares”. Essas possibilidades certamente dependerão das normas de regulação que, por sua vez, tendem a ser muito herméticas em espaços e lugares que não estimulam as contradições próprias das múltiplas alternativas de interpretação do mundo. 
Hargreaves (1999) diz que a posição e a importância social da formação de professores definem-se, em parte, pelos espaços que são criados para ela ao longo do tempo. Por essa razão, as tentativas para mudar o estatuto e a importância social dessa formação implicam em alterar a posição e o lugar onde ela se dá. 0 esforço político realizado, para garantir a formação de professores das séries iniciais no âmbito da universidade, foi decorrente do reconhecimento da importância dessa fase de escolarização, exigindo a presença de um professor bem qualificado.

Essa formação foi convertida em algo menos periférico e sujeito à marginalização. Tornou-se mais relacionada com os espaços de conhecimento e cultura e aberta à compreensão e à comunicação com o mundo. Entretanto, ainda encontra dificuldades em garantir o status profissional desejado para o professor. Como é fácil perceber, a discussão de fundo extrapola a dimensão técnica e objetiva. Envolve questões políticas e, nessa condição, provoca reações e polêmica, incluindo a discussão acadêmica.

As reações às políticas de desqualificação da formação docente não tardaram a vir. Assumindo a docência como uma ação complexa (CUNHA, 2004; SEVERINO 2006), os movimentos constituídos e a literatura da área explicitaram a inconformidade com as propostas legais, que se propunham a reduzir a função docente a parâmetros predeterminados, questionando a legitimidade da universidade como espaço de formação.

Novamente, desprestigiava-se uma condição cultural, tomando o universal como padrão para o local. As políticas regulatórias fizeram uso da avaliação externa para definir, de forma reducionista, o que se constitui como valor na educação e a consequente burocratização do trabalho docente impactou o exercício da profissão. Os estudos relacionados aos conceitos de intensificação e mal-estar docente constituíram-se academicamente. Estudiosos como Apple, Hargreaves, Corrêa e Matos deram importantes contribuições ao tema que, no plano nacional, tem importantes seguidores.
Esses estudos vêm se ampliando a partir dos desafios que o exercício da docência enfrenta. A violência, a drogadição e a crise de autoridade são problemas da sociedade contemporânea que afetam significativamente a escola e impactam o tradicional papel do professor. Os baixos salários levam ao fenômeno da intensificação e as condições não condizentes de trabalho influenciam a autoestima dos docentes, sendo parte substancial das mazelas que se instalam nas suas trajetórias profissionais. Esses fenômenos ratificam a posição de que a reflexão a respeito da formação e o exercício docente exige uma relação intrínseca com o contexto social, seus valores e tensões, explicitando a constante atualidade de sua discussão.

Convivendo com a produção acadêmica de valorização da docência na sua complexidade cultural, a vertente dos estudos pós-estruturalistas também está presente contemporaneamente, nas pesquisas acerca da formação de professores. Apoiados em autores como Foucault, Deleuzze, Guatarri, Apple e Larrosa, no âmbito internacional, logo esses estudos foram ampliados com as contribuições nacionais, das quais se destacam os aportes de Veiga Neto, Moreira, Silva, Costa, Corazza (2006), Garcia e outros.

0 professor e suas formas de ser e agir estão subordinados a um regime de verdade produzido pelas teorias críticas, tendo efeitos de poder e de verdade específicos sobre os processos de subjetivação docente, relacionados a um dever moral. 0 questionamento das teorias críticas centra seu interesse nos processos de subjetivação e nas questões de governabilidade implicadas na docência. Há, portanto, um especial relacionamento entre as teorias de currículo e a docência.

Contraditoriamente, e podendo acenar como uma forma de resistência, as teorias que valorizam a experiência e a capacidade reflexiva dos professores instalaram-se de forma exponencial nos cursos de formação e na orientação das pesquisas educacionais. As contribuições de Schön (1983) foram as primeiras a popularizar a ideia de que o conhecimento 
derivado da pesquisa experimental, que ele denominou de racionalidade técnica, não serve para o enfrentamento de problemas cotidianos do ensinar e do aprender.

Em contraponto, o autor propôs o que denominou epistemologia da prática, ou seja, assumiu que o contato e a interação com a prática docente pode gerar conhecimento, sempre que os professores se impliquem em ciclos de reflexão e diálogo com os problemas da prática. Nesse caso, reconhece-se que os professores produzem conhecimentos, ao cotejar a prática com a teoria e o conceito de saberes docentes se instalou num possível contraponto ao sentido dado pelas políticas neoliberais ao termo competências. Autores como Tardif (2002), Nóvoa (1992), Marcelo Garcia (1999) e Gauthier (1999) tiveram suas ideias acolhidas no Brasil e inspiraram estudos como os de Pimenta (1999), Ramalho (2004), Cunha (2006, 2010), para citar alguns.

Essa tendência, mesmo que majoritariamente aceita pelos pesquisadores e formadores de professores no Brasil, foi questionada por estudiosos do campo da filosofia, que alertavam para o perigo de implantar uma visão pragmática na formação, denunciando a possibilidade do recuo da teoria (MORAES, 2003). Entretanto, essa posição - ao cumprir um papel importante contra o reducionismo provocou o aprofundamento de investigações e práticas que aliaram teoria e prática como possibilidade de formação.

0 principal mérito da epistemologia da prática refere-se ao reconhecimento do trabalho docente como fonte de saberes e da complexidade da docência, sempre atingida por contingências contextuais. Como decorrência dessa tendência, instalaram-se com significativa presença no campo da formação de professores as estratégias de narrativas culturais e a compreensão do conceito de desenvolvimento profissional, que foram substituindo e englobando os anteriores relativos à formação continuada e formação permanente.

0 foco da mudança relaciona-se com a aceitação de que a formação é um processo subjetivo, ou seja, o professor se forma como uma condição de sua mobilização para tal (NÓVOA, 1994). Os estímulos externos podem ser importantes, mas precisam contar com o significado que o professor atribui à experiência de formação. Reconhece-se que essa experiência inclui as trajetórias de vida, os referentes culturais e os valores sociais em um amálgama de possibilidades de construção da profissionalidade docente, sendo entendida como a profissão em ação.

Certamente, o exercício de realizar uma análise temporal e a ousadia de organizar tendências que expressassem o movimento da formação de professores que atingiram o Brasil contemporâneo é complexo e arriscado. Os referentes emergem da visão do organizador e assumem o aspecto restritivo que essa condição inclui. Corresponde a uma possibilidade aleatória que, em nenhum momento, pretende ser uma expressão única de verdade. Trata-se de um exercício, entre outros, cuja finalidade é contribuir, especialmente visando às novas gerações, para que possam ter uma ideia de percurso, ao analisar o tema da formação de professores.

É justamente com o mesmo intuito e ousadia, com que foram sintetizadas as tendências que se manifestam no campo da formação de professores, que elaboramos o quadro 1.

Frente a esse quadro, é fácil perceber que os esforços que marcaram as rupturas epistemológicas, culturais e políticas no campo da educação e da formação de professores estiveram sempre em tensão. Ainda frágeis e minoritárias, elas procuravam afirmar-se no campo acadêmico, com toda a dificuldade decorrente da presença dominante sendo que, em geral, coexistiam e, algumas vezes, amalgamavam-se em novos contornos.

Boaventura de Sousa Santos (2000, p.344) afirma que "a luta paradigmática é, no seu conjunto, altamente arriscada”, pois exige uma subjetividade emergente que envolve ruptura epistemológica e societal. Para o autor, "formas alternativas de conhecimento geram práticas alternativas e vice-versa" 
Quadro 1 - Tendências investigativas na formação de professor

\begin{tabular}{|c|c|c|}
\hline Tendências & Estudos & Período \\
\hline Psicologia Comportamental & Valor profissional medido pela capacidade de fazer os alunos compreenderem as informações & 1960/70 \\
\hline Interacionista & $\begin{array}{l}\text { A medida da influência do comportamento do professor (verbal e interativo) sobre o aluno } \\
\text { revela sua eficácia. }\end{array}$ & 1960/70 \\
\hline Psicologia Cognitivista & $\begin{array}{l}\text { A ação do professor relaciona-se com os processos de pensamento dos alunos e a construção } \\
\text { das habilidades de ensino. Evolui para o impacto da perspectiva epistemológica construtivista. }\end{array}$ & 1970/80 \\
\hline Psicologia Afetiva & $\begin{array}{l}\text { A afetividade do educador, seus traços de personalidade, interesses e autoconceito são } \\
\text { básicos para a construção da profissionalidade e das suas formas de ensinar. }\end{array}$ & $1970 / 80$ \\
\hline Política Filosófica & $\begin{array}{l}0 \text { professor é entendido dentro da estrutura de poder da sociedade, na qual sua identidade é } \\
\text { uma construção social. Competências técnica e política se aliam. }\end{array}$ & 1980 \\
\hline Política Antropológica & $\begin{array}{l}0 \text { professor é um sujeito culturalmente produzido e politicamente situado. Sua história e } \\
\text { condição de trabalho resignificam a sua formação. }\end{array}$ & $1980 / 90$ \\
\hline $\begin{array}{l}\text { Política Sociológica/ } \\
\text { Culturalista }\end{array}$ & $\begin{array}{c}\text { A profissionalização do professor e sua condição de trabalho na organização da sociedade } \\
\text { capitalista, sua condição de gênero, classe e etnia tem profundos significados nas suas } \\
\text { práticas sociopedagógicas. }\end{array}$ & 1980/90 \\
\hline $\begin{array}{c}\text { Política } \\
\text { Pós-estruturalista }\end{array}$ & $\begin{array}{l}\text { 0 professor e suas formas de ser e agir estão subordinados a um regime de verdade } \\
\text { produzido pelas teorias críticas, tendo efeitos de poder e de verdade específicos sobre os } \\
\text { processos de subjetivação docente, relacionados a um dever moral. Centra seu interesse nos } \\
\text { processos de subjetivação e nas questões de governabilidade. }\end{array}$ & 1990/2000 \\
\hline Política Neoliberal & $\begin{array}{l}\text { O professor é preponderantemente um gestor de pedagogias predeterminadas em forma } \\
\text { de competências a serem alcançadas pelos estudantes, na perspectiva da produtividade. É } \\
\text { atingido por um processo de proletarização e desqualificação progressiva pelo esvaziamento } \\
\text { de sua condição intelectual. }\end{array}$ & $\begin{array}{l}\text { Final de } 1990 \text { e } \\
\qquad 2000\end{array}$ \\
\hline $\begin{array}{l}\text { Políticas centradas na } \\
\text { epistemologia da prática }\end{array}$ & $\begin{array}{l}0 \text { professor é um sujeito reflexivo que toma a prática como ponto de partida da formação e } \\
\text { da sua profissionalidade, resignificando contextualmente a teoria. Assume a autoformação } \\
\text { como princípio e a reflexão como possibilidade de desenvolvimento. Considera os contextos } \\
\text { institucionais e sociais em que atua. }\end{array}$ & $\begin{array}{c}1990 \text { e } \\
\text { anos } 2000\end{array}$ \\
\hline $\begin{array}{l}\text { Narrativas culturais e } \\
\text { desenvolvimento profissional }\end{array}$ & $\begin{array}{l}0 \text { professor age com base nos saberes estruturais, provenientes de diferentes fontes } \\
\text { e contextos. Constrói seus saberes a partir das múltiplas influências de formação, em } \\
\text { cotejamento com o contexto cultural e institucional onde atua. }\end{array}$ & $\begin{array}{l}\text { Anos } \\
2000\end{array}$ \\
\hline
\end{tabular}

Fonte: dados da pesquisa.

(SANTOS, 2000, p. 344), perpassando o conceito de subjetividade, que se constitui como o grande mediador entre conhecimento e práticas. Certamente, são essas as tensões contemporâneas para a formação de professores e todos os movimentos e alternativas revelarão a complexidade que demandam.

As diferentes tendências tiveram significativos impactos nas pesquisas educacionais e essas, por sua vez, também exerceram um papel de protagonismo nas mudanças paradigmáticas. Quando se toma o pressuposto de que a pesquisa pode ser um elemento-chave para a formação emancipadora, está se adotando a ideia de coerência entre os processos investigativos e uma proposição valorativa de educação. Na medida em que o paradigma da racionalidade técnica foi dando lugar à compreensão do fenômeno educativo como produzido social e culturalmente, houve significativas mudanças nas formas de produzir conhecimento sobre educação.

As pesquisas continuam abordando os temas clássicos da formação de professores, incluindo a formação inicial e continuada, os saberes em constituição na prática profissional e as condições de profissionalização. Reconhecer o espaço de trabalho como lugar de formação redundou em uma tendência significativa de 
pesquisar o docente em seu contexto de atuação, em que ele é reconhecido como produtor de saberes e, ao mesmo tempo, responde, enquanto produzido, às condições objetivas de existência e profissionalização. Nessa direção, os pressupostos investigativos que assumem a dimensão cultural têm sido recorrentes, porque melhor respondem às exigências epistemológicas.

Outra vertente exponencial no campo da formação de professores refere-se à incorporação da vertente das epistemologias da prática, que inseriram termos como professor reflexivo e professor investigador. Essa vertente estimulou estudos sobre o professor aprendente. Trata-se claramente da intenção de pesquisar o professor como sujeito epistêmico, que vai reconfigurando seus saberes em função dos desafios profissionais que a prática lhe impõe.

É possível discutir a ideia de uma epistemologia da prática que não se identifıque com um praticismo inconsequente, facilmente criticado pela possibilidade de constituir-se afastado da teoria. Nessa perspectiva, estarse-iam fragilizando os processos de formação docente, por meio do apressamento das propostas curriculares. No atual contexto, em que as políticas globalizadoras e economicistas pressionam para uma formação rápida e de massas, essa é uma ameaça significativa. Entretanto, esse argumento não tem servido para anular a importância de teorias que tomam a epistemologia da prática como eixo articulador da formação. Em especial, isso ocorre graças às constantes denúncias da fragilidade do modelo de formação em que se propunha uma teorização desconectada da prática e do cotidiano dos docentes e alunos.

André (2008), em recente estudo, apontou temas que vêm sendo apresentados e discutidos nos Grupos de Trabalho da Associação Nacional de Pós-Graduação e Pesquisa em Educação (ANPEd). Mesmo se tratando de uma amostra da realidade nacional, mas considerando-se a legitimidade da fonte, pela sua importância e representatividade na área da educação, os dados podem ser úteis para aqui serem apresentados.
No referido estudo, os temas mais recorrentes estavam relacionados a algumas dimensões, tais como:

a) práticas pedagógicas protagonizadas pelos professores, que evidenciam capacidades didáticas, incluindo, principalmente, os processos de avaliação da aprendizagem, o ensino de disciplinas específicas, o uso do livro didático e a apropriação das Tecnologias da Informação e Comunicação (TICs) aos processos de ensinar e aprender;

b) representações e concepções docentes sobre os atores do processo educativo bem como das políticas que interferem e regulam a educação escolarizada;

c) o trabalho docente e as condições de profissionalização dos professores, incluindo as dimensões da autonomia e autogestão nos processos de educação continuada;

d) as práticas e os programas de formação de professores, incluindo a formação inicial, e a continuada, na sua dimensão política e pedagógica; $\mathrm{e}$

e) a importância da pesquisa como ferramenta da docência de qualidade, explorando teorias e práticas que municiam o professor para esse protagonismo.

Compreendendo os limites das informações traçadas acima, é possível assumir, porém, que elas indicam posições contemporâneas e servem como balizadores da área. Vale ressaltar que essa descrição tanto aponta relevâncias como revela silêncios. Percebe-se uma ausência de temas relacionados às políticas públicas e de carreira, às dimensões filosófico-políticas da docência, à dimensão sociológica do trabalho do professor e algumas outras que compõem o espectro de temas relacionados ao campo.

Todas as fases que marcam as tendências dos estudos a respeito da formação de professores produziram conceitos e apresentaram-se como produtos e produtoras das ações formativas, influenciando e sendo influenciadas pelas políticas, legislações e culturas.

A temática da formação de professores coloca-se como um tema inesgotável e é sempre 
instigadora na educação superior. Provocou e vem provocando diferentes abordagens de estudo e exigindo desdobramentos na sua análise e compreensão. As exigências da profissionalização reabriram reflexões específicas acerca da formação continuada dos docentes de todos os níveis, as quais provocaram a necessidade de repensar a formação inicial. Ambas continuam exigindo esforços e estimulando o espírito investigativo da base acadêmica.
Parece que a necessidade de estudar o professor e sua formação é tão permanente quanto inexorável é a ideia de processo na sua condição humana, em sua organização social. As mudanças na sociedade definirão sempre novos desafios para a educação dos homens e, como decorrência, diferentes aportes no papel e formação de professores. Esse se coloca como um permanente desafio para a pesquisa e para a universidade.

\section{Referências}

ABRAMO, Perseu. 0 professor, a organização corporativa e a ação política. In: CATTANI, Denice et al. (Orgs.). Universidade, escola e formação de professores. São Paulo: Brasiliense, 1987.

ANDRÉ, Marli. Tendências da pesquisa e do conhecimento didático no início dos anos 2000. Anais do XIV ENDIPE. Porto Alegre: XIV ENDIPE, EDIPUCRS, 2008, p.487-499.

APPLE, Michael. Educação e poder. Porto Alegre: Artes Médicas, 1989.

ARROYO, Miguel. Mestre, educador, trabalhador: organização do trabalho e profissionalização. 1985. Tese (Titular) - Universidade Federal de Minas Gerais, Belo Horizonte, 1985.

. Profissão de mestre. São Paulo: Cortez, 2004.

ASCHNER, Mary. The analysis of verbal interaction in the classroom. In: BELLACK, Arno (Org.). Theory and research in teaching. New York: Bureau of Publications, Teachers College, Columbia University, 1963, p. 53-78.

COLL, César. Psicologia y curriculum. Barcelona: Laia, 1987.

CORAZZA, Sandra. Artistagens: a filosofia da diferença e a educação. Belo Horizonte: Autêntica, 2006.

COSTA, Marisa Vorraber. Gênero, classe e profissionalismo no trabalho de professoras e professores de classe populares. Tese (Doutorado) - Universidade Federal do Rio Grande do Sul, Porto Alegre, 1995.

CUNHA, Maria Isabel da. 0 bom professor e sua prática. Campinas: Papirus, 1989.

. A pesquisa qualitativa e a didática. In: OLIVEIRA, Maria Rita (Org.). Didática: ruptura, compromisso e pesquisa. Campinas: Papirus, 1993.

A docência como ação complexa: o papel da didática na formação de professores. In: ROMANOWSKI, Joana et al. (Org.). Conhecimento local e conhecimento universal: pesquisa, didática e ação docente. Curitiba: Universitária Champagnat, 2004, p. 31-42. 2006, p. 354

Verbetes: formação inicial e formação continuada. Enciclopédia de pedagogia universitária. Brasília: MEC/INEP,

CUNHA, Maria Isabel da. Trajetórias e lugares de formação da docência universitária: da perspectiva individual ao espaço institucional. Araraquara: Junqueira e Marins Editora, 2010. 
ENGUITA, Mariano. A ambigüidade da docência: entre o profissionalismo e a proletarização. Teoria e Educação, Porto Alegre, n. 4, p. 41-61, 1991.

ESTEVÃO, Carlos. Formação, gestão, trabalho e cidadania. Contributos para uma sociologia crítica da formação. Educação e Sociedade, Campinas, ano XXII, n. 77, p. 185-206, dez. 2001.

FAZENDA, Ivani. A pesquisa em educação e as transformações do conhecimento. Campinas: Papirus, 1995.

FELDENS, Maria das Graças. Educação de professores: tendências, questões e prioridades. Tecnologia Educacional, n. 7, p. 16-26, nov./dez. 1984.

FLANDERS, Ned A. Teacher influence, pupil attitudes and achievement. Minneapolis: University of Minnesota, 1960.

FREIRE, Paulo. Extensão ou comunicação. 10 ed. Rio de Janeiro: Paz e Terra, 1992.

GADOTTI, Moacir. A questão da educação e formação do educador: aprendendo com minha própria história. Em Aberto, Brasília, MEC/INEP, n. 34, 1980.

GAGE, Norberto (Org.). Handbook of research on teaching. Chicago: Rand McNally and Co., 1963.

GALLAGHER, James; ASCHNER, Mary Jane. A preliminary report: analysis of classroom interaction. Merril palmer quarterly of behavior and development, n. 9, p. 94-183, 1963.

GARCIA, Carlos Marcelo. Formação de professores: para uma mudança educativa. Porto: Porto Editora, 1999.

GAUTHIER, Jacques. 0 que é pesquisar: entre Deleuze e Guattari e o candomblé. Pensando mito, ciência, arte e culturas de resistência. Educação e Sociedade, Campinas, ano XX, n. 77, dez. 1999.

GIDDENS, Anthony. La constituición de la sociedad. Madrid: Alianza, 1984.

GUERRERO, Antonio Seron. Manual de sociología de la educación. Madri: Editorial Sistesis, 1992.

HARGREAVES, Andy. Hacia una geografía social de la formación docente. In: PÉREZ GOMES, Ángel; BARQUIN RUIZ, Javier; ÂNGULO RASCO, José Felix (Orgs.). Desarrollo profesional del docente: política, investigación y práctica. Madrid: Akal, 1999.

HYPOLITO, Álvaro. Processo de trabalho na escola: algumas categorias para análise. Teoria e Educação, Porto Alegre, n. 4, p. 3-21, 1991.

Reestruturação educativa e trabalho docente: autonomia, contestação e controle. In: HYPOLITO, Álvaro; VIEIRA, Jarbas; GARCIA, Maria Manuela (Orgs.). Trabalho docente: formação e identidades. Pelotas: Seiva, 2002, p. 273-283.

ISAIA, Silvia. Processo formativo docente. Verbete. Enciclopédia de pedagogia universitária. Brasília: MEC/INEP, 2006, p. 351.

LEMBO, John M. Por que falham os professores. São Paulo: EPU/EDUSP, 1975.

LOPES, Eliane Marta. A educação da mulher: a feminilização do magistério. Teoria e Educação, Porto Alegre, n. 4, p. 22-40, 1991.

LOURO, Guacira. Magistério de $1^{\circ}$ grau: um trabalho de mulher. Educação e Realidade, Porto Alegre, n. 2, p. 31-39, jul./dez. 1989 .

LÜCKESI, Cipriano. Equívocos teóricos na prática educacional. Rio de Janeiro: Associação Brasileira de Tecnologia Educacional, 1983. (Estudos e pesquisa).

LÜDKE, Menga; ANDRÉ, Marli. Pesquisa em educação: abordagens qualitativas. São Paulo: EPU, 1986.

MARTINS, Pura Lucia Oliver. Didática teórica / didática prática: para além do confronto. São Paulo: Loyola, 1982.

MELLO, Guiomar. Magistério de $\mathbf{1}^{\circ}$ grau: da competência técnica ao compromisso político. São Paulo: Cortez, 1982. 
MEUX, Milton. Studies of learning in the: school setting. Review of Education Research, n. 5, 32, 1997.

MORAES, Maria Célia Marcondes (Org.). Iluminismo às avessas: produção de conhecimento e políticas de formação docente. Rio de Janeiro: DP\&A, 2003.

MORRISON, Arnold; MCINTYRE, Donald. Schools and socialization. Harmondsworth: Penguin Books, 1971.

MOSQUERA, Juan. 0 professor como pessoa. Porto Alegre: Sulina, 1976.

NOSELLA, Paolo. Compromisso político como horizonte da competência técnica. Educação e Sociedade, São Paulo, n. 14, p. $91-107$, abr. 1983

NÓVOA, Antônio. Formação de professores e profissão docente. In: Os professores e sua formação. Lisboa: Dom Quixote, 1992.

. Educação e formação ao longo da vida: entrevista. São Paulo: CRE Mario Covas, entrevista concedida por e-mail em out. 2004. Disponível em: <http:www.crmariocovas.sp.gov.br>. Acesso em: mar. 2012.

PENIN, Sonia. A aula: espaço de conhecimento, lugar de cultura. Campinas: Cultura, 1994.

PEREZ GOMEZ, Angel I. La cultura escolar en la sociedad neoliberal. Madri: Morata, 2000.

PERRENOUD, Philippe. Práticas pedagógicas, profissão docente e formação: perspectivas sociológicas. Lisboa: Dom Quixote, 1993.

PESSANHA, Eurize. Ascensão e queda do professor. São Paulo: Cortez, 1994.

PIMENTA, Selma Garrido. 0 estágio na formação de professores. São Paulo: Cortez, 1994.

. (Org.). Saberes pedagógicos e atividade docente. São Paulo: Cortez, 1999.

PIMENTEL, Maria da Glória. 0 professor em construção. Campinas: Papirus, 1993.

POSTIC, Marcel. Observação e formação de professores. Coimbra: Almedina, 1979.

RAMALHO, Betânia et al. Formar o professor, profissionalizar o ensino: perspectivas e desafios. 2. ed. Porto Alegre: Sulina, 2004.

REMMERS, J.; GAGE, Norberto. Paradigms for research on teacher affectiveness. Review of Research in Education, v.5, n.1, p. 163-168, jan. 1977.

RODRIGUES, Neidson. Por uma nova escola: 0 transitório e o permanente na educação. São Paulo: Cortez, 1985.

ROGERS, Carl. Liberdade para aprender. Belo Horizonte: Interlivros, 1971.

SACRISTAN, José Gimeno; PEREZ, Gomes. La enseñanza: su teoría y su práctica. Madri: Akal, 1989.

SANT’ANNA, Flávia. 0 processo ensino-aprendizagem na perspectiva humanista. Porto Alegre: Amma, 1976.

SANTOS, Milton. A aceleração contemporânea: tempo mundo e espaço mundo. In: et al. (Orgs.). Fim de século e globalização. São Paulo: Hucitec-Anpur, 1997.

SAVIANI, Demerval. Ensino público e algumas falas sobre a universidade. São Paulo: Cortez, 1981.

SCHÖN, Donald. The reflective practitioner. London: Temple Smith, 1983.

SCHULMAN, Lee. Paradigmas y programas de investigación en el estudio de la enseñanza: una perspectiva contemporánea. In: WITTROCK, Merlin. La investigación de la enseñanza: enfoques, modelos y métodos. Barcelona: Paidós, 1989. 
SEVERINO, Antonio J. Pressupostos filosóficos da formação e da prática do educador. Cadernos de Educação, Pelotas, FaE/JFpel, Ano 15, n. 27, p. 37-54, jul./dez. 2006.

SILVA, Tomaz T. 0 projeto educacional moderno: identidade terminal? In: VEIGA-NETO, Alfredo. Crítica pós-estruturalista e educação. Porto Alegre: Sulina, 2000.

SANTOS, Boaventura de Sousa. A crítica da razão indolente: contra o desperdício da experiência. São Paulo: Cortez, 2000.

TARDIF, Maurice. Saberes docentes e formação profissional. Petrópolis: Vozes, 2002.

VARELA, Julia. A maquinaria escolar. Teoria e Educação, Porto Alegre, n. 6, p. 68-96, 1992.

VEIGA, IIma Passos A. (Org.). Repensando a didática. Campinas: Paipirus, 1988.

VIEITZ, Candido. Os professores e a organização da escola. São Paulo: Cortez, 1982.

ZEICHNER, Kenneth. Novos caminhos para o practicum: uma perspectiva para os anos 90. In: NÓVOA, Antonio (Org.). Os professores e a sua formação. Lisboa: Dom Quixote, 1992.

Los profesores como profesionales reflexivos y la democratización de la reforma escolar. CONGRESO INTERNACIONAL

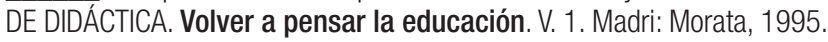

Recebido em: 28.08.2012.

Aprovado em: 24.04.2013.

Maria Isabel da Cunha é doutora em Educação. Professora do Programa de Pós-Graduação em Educação da Universidade do Vale do Rio dos Sinos. Pesquisadora 1 A do Conselho Nacional de Desenvolvimento Científico e Tecnológico (CNPq). 